\title{
Driver Perception on Speed Limit Sign
}

\author{
Dani Marga E , Andyka Kusuma , and Tri Tjahjono \\ Universitas Indonesia, Kampus Baru UI depok - 16424 Indonesia
}

\begin{abstract}
Purpose of this research is to evaluate vehicle driver especially four wheel vehicle to know driver criteria on speed limit, especially on four wheel vehicle. This research takes the route from Surabaya to Jombang across toll road. This research is conducted with counting each vehicle speed with looking on speed standard on the respective road. The result shown that majority of the driver still not care about speed limit, but driver still care only for the speed not for their safety. For dominant speed is around $80-100 \mathrm{~km} /$ hour. In this research also counts driver perception percentage that caused by driver who surpass the determined limit or below the limit. It could be concluded that by motoric behavior, we will decide to overspeed or obey the rules that shown by speed limit sign that also has an effect and driver perception on driving affect to driver situation before or while on trip using vehicle.
\end{abstract}

Keywords : Driver perception, Speed signs, Speed, Safety driving

\section{Introduction}

Traffic violations are a form of events that are always experienced by drivers who often cause problems on the highway. This can be seen from the indication of violations that continue to occur, and even tends to increase every year.

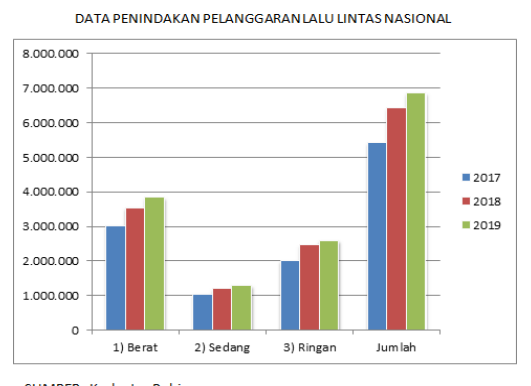

Fig.1. Traffic Violation Enforcement Diagram

Based on the above table The increase in violations that occurred should be able to be suppressed or even eliminated. Awareness of driving safety should not only be for himself, but also to protect safety for others. Transportation drivers have the principle of being able to drive to reach their destination in the minimum time possible with or without a vehicle. Increased vehicle speed greatly affects the time and distance needed to stop and the possibility of mistakes made by the driver. High speed and exceeding the allowable limit are factors that cause accidents faced by many countries (Elliot, Armitage, \& Baughan, 2005; Nilsson, 2004). Speed limits vary by country. Legislative Audit Division in Montana (1997). The higher the speed, the greater the stopping distance needed. Most drivers have the impact of high speed, is the risk of motorists when an accident occurs. According to Law No. 22 of 2009 concerning Road Traffic and Transportation, the maximum speed limit is adjusted to the area of 
settlements, urban areas, inter-city roads and highways while in the Minister of Transportation Regulation No. 111 of 2015 Determination of speed limits set nationally and stated with traffic signs: a.) At least 60 (sixty) $\mathrm{km} \mathrm{/} \mathrm{h}$ in free flow conditions and at the highest 100 (one hundred) km / h for expressways; b.) A maximum of 80 (eighty) km / hour for intercity roads; c.) A maximum of 50 (fifty) $\mathrm{km} /$ hour for urban areas; and D. ) At a maximum of 30 (thirty) $\mathrm{km} /$ hour for residential areas. The trigger of the lack of discipline of drivers regarding speed limits is due to the lack of understanding of motorists in traffic signs so that it is still often found that many drivers do not obey traffic rules (Sudarsono 2005: 344). Seeing the problem above, our researchers hope that in order to reduce accidents and violations of traffic on the highway, it is necessary to provide an understanding of the driver regarding traffic signs in accordance with the procedures for driving a vehicle.

\section{Literature Review}

Speed (Khisty, Lall, 2003) is defined as a lane of movement, such as distance per unit time, generally in miles / hour (mph) or kilometers / hour ( $\mathrm{km} /$ hour), and can be measured as: Design speed is a speed specifically used to determine various features of the geometry design of the road. To achieve the desired level of security, mobility and efficiency. However, it must still pay attention to the quality of the environment, economy, aesthetics and sociopolitical impacts, thus the speed of design used must be in accordance with conditions, exceptions are applied to local roads where speed restrictions often have to be considered. The design speed used must be calculated as carefully as possible to match the function of the highway, topography, surrounding land use, and anticipated free flow velocity.

There are several things that must be underlined, the design speed must be adjusted to the average speed. In addition, the driver usually adjusts speed not based on how important the highway is concerned but is more limited by the physical limitations and traffic conditions on the road. The consistent design speed on a long road is an important factor. Drastic changes in speed must be avoided, and if changes like this are really needed (due to topographic factors), changes in speed must be gradual. Drivers must be warned of what will happen, through means such as speed limit signs and speed signs around corners. In short, according to AASHTO (2001), that is the speed at which drivers are observed operating their vehicles during free flow conditions, the maximum limit for speed designs that are low or lower are $45 \mathrm{~km} / \mathrm{h}$ and the minimum limit for high design speeds is $50 \mathrm{~km} / \mathrm{h}$. Whereas based on the Toll Road Geometry Standard $(07,2009)$, the design speed for a road section is considered to be the same along the road section. The design speed for each road function is according to the speed of the plan. The speed of the planned ramp of the intersection that connects the toll road with the toll road (Interchange System) must meet the conditions as in Table 1 below:

Table 1. Interchange System

\begin{tabular}{ccccc}
\hline $\begin{array}{c}\text { VR jalan tol I } \\
\text { (km/jam) }\end{array}$ & \multicolumn{4}{c}{$\begin{array}{c}\text { VR jalan tol II } \\
\text { (Km/jam) }\end{array}$} \\
\cline { 2 - 5 } & $\mathbf{1 2 0}$ & $\mathbf{1 0 0}$ & $\mathbf{8 0}$ & $\mathbf{6 0}$ \\
\hline 120 & $60-80$ & & & \\
100 & $60-80$ & $60-80$ & & \\
80 & $40-80$ & $40-60$ & $40-60$ & \\
60 & $40-80$ & $40-60$ & $40-60$ & $40-60$ \\
\hline \multicolumn{4}{c}{ Src: Standart Geometri Jalan Tol, Dep.PU, 2009 }
\end{tabular}


Table Error! No text of specified style in document 1Kecepatan rencana ramp pada simpang susun sistem Operating Speed. For travelers, speed is one of the most important factors for choosing a route or determining transportation. Economic factors, travel time and comfort are closely related to speed. Road speed is generally heard by conditions such as the ability of drivers who use the highway, the characteristics of vehicles that use the highway, the physical characteristics of the road and the shoulders, the weather, the presence of other vehicles and speed requirements (both legal requirements / due to controlling equipment). The combined effects of these conditions determine the speed on the part of the highway concerned.

The main purpose of making a highway is to meet the needs of users in a way that is as safe and economical as possible. Therefore, we must find a speed value that is suitable for all drivers. Operating speed can be seen as the highest total speed at which speed a driver can pass over certain highways under friendly weather conditions and under normal traffic conditions from one section of the road to another. The most commonly used measure of operational speed is the 85 th percentile of the observed speed distribution for a particular geometric location or feature.

\subsection{Motion Speed}

Motion speed can be interpreted as the actual vehicle speed on a section of the highway where the magnitude is equal to the distance traveled by the vehicle divided by the time the vehicle is in motion. When the vehicle is moving continuously, the spot speed (speed at a place) on a road segment will be equivalent to the average speed of movement. The average spot speed is the arithmetic average of all traffic speeds at a particular location in a certain vulnerable time.

$$
\begin{array}{ll} 
& \\
V t=\frac{\sum_{i=1}^{n} V i}{n} \\
\mathrm{Vt} & =\text { Average Speed } \\
\mathrm{Vi} & =\text { Spot Speed } \\
\mathrm{N} & =\text { Number of Vehicles Observed }
\end{array}
$$

Another way to determine the average speed is to determine the average speed of the local space (space mean speed $=$ SMS), where the use of average travel time basically takes into account the average based on the length of time used by each vehicle in "space". The speed value is generated by dividing the distance to time in units of seconds and then converted to speed per hour by multiplying the speed value per second x 3600 seconds / 1000 meters. Mathematically the average speed of this space can be calculated as follows:

$$
V_{S}=\frac{L}{\sum_{i=1}^{n} \frac{t i}{n}}=\frac{n L}{\sum_{i=1}^{n} t i}
$$

$\mathrm{V} \quad=$ Average Space speed

$\mathrm{L} \quad=$ The length of the observed road segment

$\mathrm{T} \quad=$ Travel time for each vehicle observed

$\mathrm{N} \quad=$ Number of observations 


\subsection{Free Flow Speed}

Free Flow Speed is the speed of traffic when density approaches zero. In practice, this speed is

the speed at which the driver feels comfortable driving under physical, environmental and traffic control conditions that are located on a non-congested highway or multi-lane highway. Determination in the field of free flow velocity is done by observing travel time during periods of low volume and this represents an actual value that will be used in the analysis of highway capacity.

\section{Methodology}

Research method that used in this research is quantitative descriptive method with searching information about current event, it's purpose is defined clearly, it's approach is planned, collecting data for formulating a report. This is appropriate with Arikunto (2006:12) opinion that said quantative research is research approach that emphasizes on using numbers, starts from data collection, data interpretation, and data presentation. The research type is Cross-Sectional Study which is a research that study a correlation of risk factors with effects, and with an approach, observation, or with data collection on particular time (point time approach). This research is conducted with analyzing traffic sign to vehicle speed and traffic accident.

Experimental Research main value is to measure effects of behavior that caused by previous behavior (Alsa 2004). Hadi (1985) said that experimental research is a research that conducted to find a consequences by a behavior that has been given purposefully by researcher. Experimental research on its principal can be defined as systematic method that create a relationship that has an causal effect (causal- effect relationship)(Sukardi 2011:179).

\section{Results}

Based on the literature study, there are some factors that affect driver comprehension about traffic sign especially maximum speed limit sign. Explanation on each factor that affect the driver can be analyzed as follows: 1) Length of Trip, is a distance that taken by a driver when driving; 2) Time of Trip; 3) Driver Psychology; 4) Weather Change. Intensity comparison data is taken from driver velocity factor to comparison of factors on speed limit sign on SurabayaJombang toll road. This data also confirm comparison data of driver velocity from speed limit literatur study. Measurement of comparison intensity from driver velocity factor using GPS on speed measurement is determined by inputing each vehicle speed with afffecting factor. Explanation from data collection is shown on table 2. below.

\subsection{Without Sign}

Table 2. Driver Speed Distribution without Speed Sign Data Collection

\begin{tabular}{cccc}
\hline Speed Range & Frequency & Relative Freq & Cum Freq \\
\hline $70-79$ & 2 & 0,0051 & 0,0051
\end{tabular}




\begin{tabular}{cccc}
\hline Speed Range & Frequency & Relative Freq & Cum Freq \\
\hline $80-89$ & 88 & 0,2256 & 0,2308 \\
$90-99$ & 150 & 0,3846 & 0,6154 \\
$100-109$ & 117 & 0,3000 & 0,9154 \\
$110-120$ & 33 & 0,0846 & 1,0000 \\
\hline Total & 390 & & \\
\hline
\end{tabular}

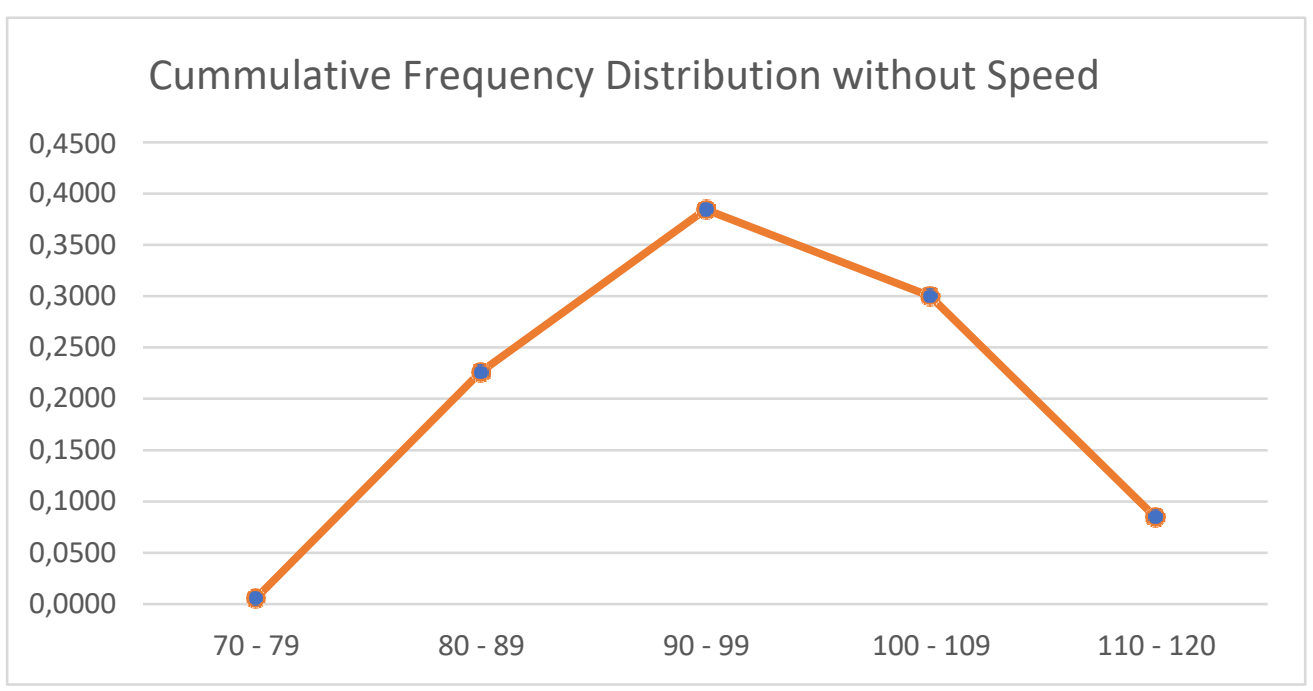

Fig.2. Cummulative Frequency Without Sign Graphic Driver Speed Distribution without Speed Sign Data Collection Table

\subsection{With Sign}

Table 3. Driver Speed Distribution with Speed Sign Data Collection

\begin{tabular}{|c|c|c|c|}
\hline Speed Range & Frequency & Relative Freq & Cum Freq \\
\hline $70-79$ & 11 & 0,0282 & 0,0282 \\
\hline $80-89$ & 268 & 0,6872 & 0,7154 \\
\hline $90-99$ & 85 & 0,2179 & 0,9333 \\
\hline $100-109$ & 25 & 0,0641 & 0,9974 \\
\hline $110-120$ & 1 & 0,0026 & 1,0000 \\
\hline Total & 390 & & \\
\hline
\end{tabular}




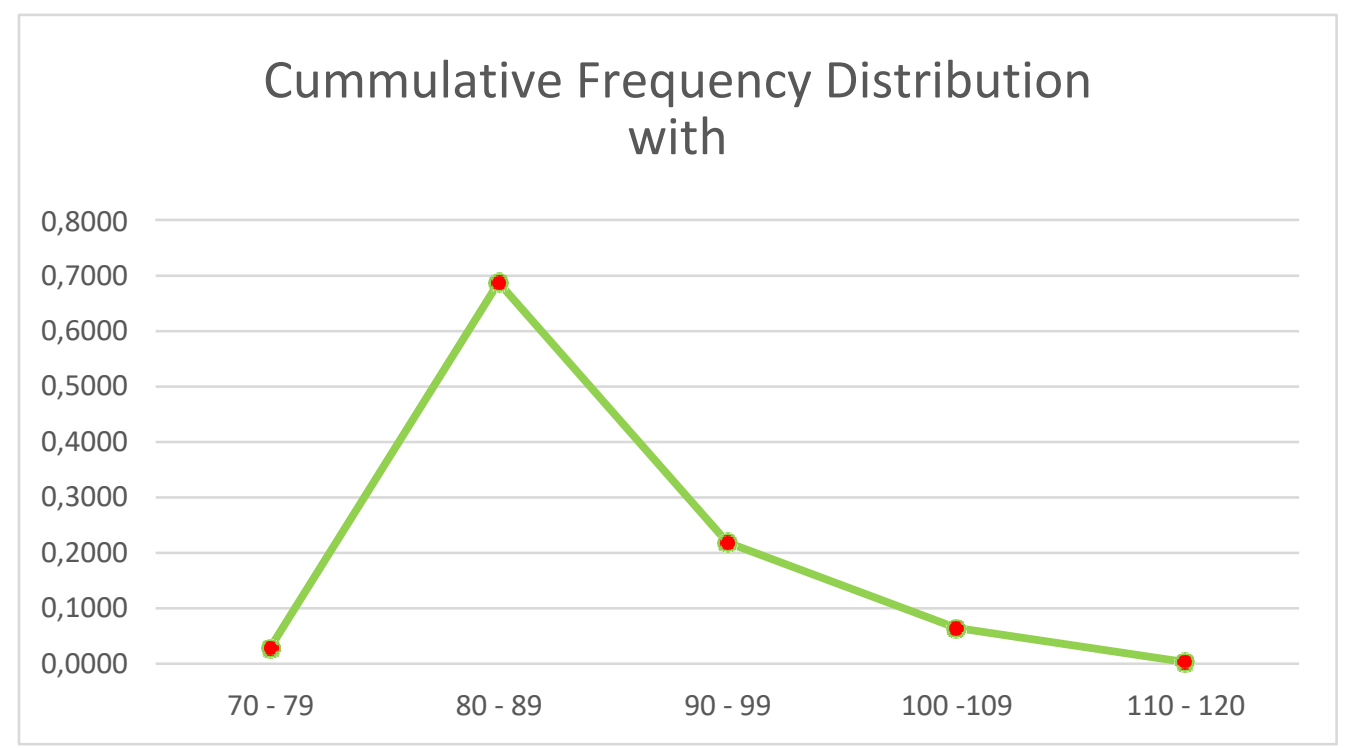

Fig.3. Cummulative Frequency With Sign Graphic

Based on data measurement that has been conducted using SPSS, it's results is very significant. Where driver speed on Surabaya-Jombang toll that not use speed limit sign and driver speed that use speed limit sign. Paired Sample T-test shown results with thumbrule $=$ Sig. 2-Tailed $<$ Alpha $(0.05) \Rightarrow$ Significant, it can be shown on picture below :

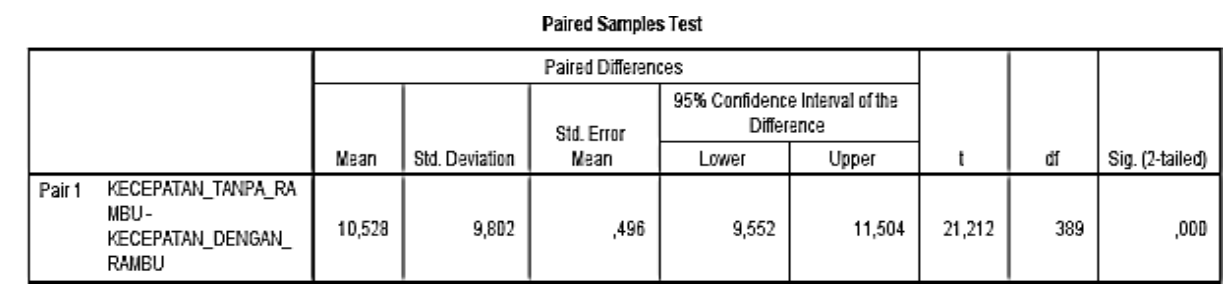

Fig.4. Paired Sample T-test Results

From the results above it can be concluded that there is a significant difference between speed without sign and speed with sign, this is stated by Sig. 2-tailed value $(0.000)$ more smaller than Alpha 5\% (0.05)

\section{Conclusion}

Based from the results, It can be concluded that:

a) Based on identification and survei results about driver perception on sign there still a lot of drivers that drive surpass determined speed limit even though speed limit sign is shown, it increase even more if there is no speed limit sign.

b) This research shown that driver perception is affecting so much to driver trip and affecting factors are correlated each other, so it can affect driver speed. 


\section{References}

[1] Anastasopoulos, P.C., 2016. Random parameters multivariate tobit and zero-inflated count data models: addressing unobserved and zero-state heterogeneity in accident injury-severity rate and frequency analysis. Anal. Methods Accid. Res. 11, 17-32.

[2] Anastasopoulos, P.C., Mannering, F.L., 2009. A note on modeling vehicle accident frequencies with random- parameters count models. Accid. Anal. Prev. 41 (1), 153-159.

[3] Babić, D., Ščukanec, A., Fiolić, M., 2014. Traffic sign analysis as a function of traffic safety on Croatian state road D3. ICTTE-International Conference on Traffic and Transportation Engineering.

[4] Babić, D., Babić, D., Macura, D., 2017. Model for predicting traffic signs functional service lifethe Republic of Croatia case study. Promet-Traffic Transport. 29 (3), 343-349.

[5] Jørgensen, F., Wentzel-Larsen, T., 1999. Optimal use of warning signs in traffic. Accid. Anal. Prev. 31, 729-738.

[6] Loo, R., 1979. Role of primary personality factors in the perception of traffic signs and driver violations and accidents. Accid. Anal. Prev. 11, 125-127.

[7] Lord, D., Mannering, F.L., 2010. The statistical analysis of crash-frequency data: a review and assessment of methodological alternatives. Transportation Research Part A 44 (5), 291-305.

[8] Mannering, F.L., Bhat, C.R., 2014. Analytic methods in accident research: methodological

[9] Madhar Taamneh, Sharaf Alkheder, 2018. Traffic sign perception among jordania drives: An evaluation study.

[10] Park, E.S., Lord, D., 2007. Multivariate Poisson-lognormal models for jointly modelling crash frequency by severity. Transp. Res. Rec. 2019 (1).

[11] Park, E.S., Lord, D., 2007. Multivariate PoisAl-Madani, H., Al-Janahi, A.R., 2002a. Assessment of drivers' comprehension of traffic signs based on their traffic, personal and social characteristics. Transport. Res. F Traffic Psychol. Behav. 5 (1), 63-76

[12] Al-Madani, H., Al-Janahi, A.R., 2002b. Role of drivers' personal characteristics in understanding traffic sign symbols. Accid. Anal. Prev. 34 (2), 185-196.

[13] Ng, A.W., Chan, A.H., 2008. The effects of driver factors and sign design features on the comprehensibility of traffic signs. J. Saf. Res. 39 (3), 321-328.

[14] Victor Muchuruza, Renatus Mussa, 2005. Nationwide survey on the positing of minimum speed limit sign on Interstate freeways.

[15] Yee Mun Leee, Siang Yew Chong, Karen Gooting, Elizabeth Sheppard, 2016 The effect of speed limit credibility on driver's speed choice. 